\title{
A errância: para além de um sintoma patológico
}

\author{
Ana Claudia Soares*1 \\ Angélica Bastos*2
}

Este artigo discute a questão da errância de forma transestrutural, como uma vicissitude presente nas diferentes estruturas clínicas, e verifica sua positividade: a possibilidade de, a partir do errar, construir-se algo novo. Com base na conexão entre psicanálise e arte, o trabalho recorre à escrita de James Joyce para investigar a errância e analisar o percurso realizado pelo escritor, inicialmente na posição de vagabundo, errante, até com sua arte inventar um lugar para si no mundo.

Palavras-chave: Psicanálise, errância, exílio, invenção

${ }^{* 1}$ Doutoranda na Universidade Federal do Rio de Janeiro (Rio de Janeiro, RJ, Br).

*2Universidade Federal do Rio de Janeiro (Rio de Janeiro, RJ, Br). 
A errância não se limita ao que podemos observar como um movimento sem destino fixo, relacionado ao nomadismo, ao errante que se põe a vagar sem rumo pelas estradas da vida, seja por motivos econômicos, seja pela marginalidade social. Embora este seja seu aspecto mais visível e negativo, basta olhar as pessoas que vivem nas ruas: trata-se de um fenômeno que abrange outros aspectos. Propomos aqui analisar o seu aspecto positivo: a possibilidade de, pelo movimento de errar, construir algo novo. E para isso nos deixaremos ensinar pelo artista James Joyce.

Esse artista foi escolhido por encarnar a figura do errante. Aqui, nos valeremos da conexão entre Psicanálise e Arte, sem esquecer que o psicanalista não visa diagnosticar o artista, mas sim aprender com ele sobre invenções possíveis diante do mal-estar na vida. Trataremos de investigar a articulação entre errância e invenção, sustentando que Joyce, a partir de sua condição de autoexilado e por sua prática de escritor, pode nos revelar o valor da errância.

\section{A questão da errância}

Errância, em sua raiz etimológica, é marcada por uma ambiguidade, uma vez que errar é um termo que, segundo o dicionário etimológico de Bloch e Wartburg (1975), comporta tanto o sentido de equivocar-se, cometer erro, extraviar-se, quanto o de caminhar, progredir, avançar. Nesta acepção aproxima-se dos viajantes. No fim do século XIX, estabeleceu-se na literatura alienista francesa uma associação entre errância e loucura, tratando os "alienados viajantes" como categoria diagnóstica. 
As fugas e viagens estranhas e repentinas, decorrentes muitas vezes de estados de alteração da consciência, sempre estiveram presentes, porém data de 1887 a publicação do primeiro caso de "fugitivo" da história, a quem um médico, o francês Philippe Tissié, dedicou uma tese específica: "Les aliénés voyageurs". Tissié relata o caso de alienação viajante de Albert D., de 26 anos, que fez numerosas viagens (Alemanha, Áustria, Rússia, Argélia etc.) ao longo de sua vida. O jovem chega chorando ao hospital onde o médico trabalhava, após haver empreendido uma viagem longa a pé. Mesmo cansado, ele não podia se impedir de partir, posto que estava "cativado por um desejo imperioso", deixando para trás família, trabalho e hábitos. Na categoria de "cativado" estariam sujeitos cuja "representação, juízo e deliberação estão normais, mas podem ser deslocados pela imposição de uma ideia fixa, imperiosa, dominante" (Tissié, 1887, p. 114). Albert tinha andado setenta quilômetros até ser preso como vagabundo.

Nesse trabalho, Tissié investiga as viagens e fugas empreendidas pelos "delirantes que andam sob o domínio de uma ideia absurda pela qual ordenam toda a sua existência" (p. 9-10). Trata-se da ideia de partir, de fugir, tomada pelo delirante, "aquele que sai da via comum e se afasta das regras da razão" (p. 13). O caso de Albert ilustra a errância tomada como sintoma psicopatológico. O Manual Diagnóstico e Estatístico de Transtornos Mentais DSM-IV cataloga esse fenômeno como 'Fuga Dissociativa'. Atualmente, no DSM-5, esse diagnóstico foi incorporado ao de 'Amnésia Dissociativa', como um especificador 'com fuga dissociativa': "Viagem aparentemente proposital ou perambulação sem rumo associada a amnésia da identidade ou de outras informações autobiográficas importantes" (2014, p. 298).

Consideramos a errância para além de um sintoma ou fenômeno patológico, pensando-a de forma transestrutural, portanto, presente em qualquer estrutura clínica, neurose ou psicose, segundo o marco psicanalítico inaugurado por Freud, não se limitando ao seu aspecto negativo, deficitário e até mesmo mortificante, que pode ser observado em pacientes psicóticos, por exemplo.

Apesar do termo 'errância' não ser explicitamente trabalhado como conceito em Psicanálise, podemos rastrear algumas pistas deixadas sobre o errar. Freud procurou o sujeito nos erros daquele que se colocava diante dele para análise e demonstrou como a psicopatologia se inscreve na vida cotidiana, ou melhor, como manifestações cuja formação obedece às mesmas leis que o sintoma neurótico se apresentam nos fenômenos mais comuns entre os falantes. Percebeu com fina agudeza que é nos lapsos, tropeços, atos falhos, que o sujeito do inconsciente se revela. 


\section{ARTIGOS}

\section{Joyce, o errante}

O escritor James Joyce é saudado como inventor de uma nova literatura. Ele transformou seu Ulysses num marco literário. Sua biografia escrita por Richard Ellmann (1989) e o vasto material literário deixado por Joyce fornecem nossas coordenadas, uma vez que, como ressaltou Lacan (1975-76/2007, p. 77), ficamos reduzidos a lê-lo pelo fato do escritor nunca ter feito análise. Dessa leitura, um ponto nos chama a atenção: a errância. Em carta datada de 29 de agosto de 1904 àquela que viria a ser sua companheira por toda a vida, Nora Barnacle, Joyce (2012b) escreveu: "Não posso fazer parte da ordem social senão como um vagabundo" (p. 37). Ele estava pronto para partir como ator ambulante, mas Nora o deteve. Porém, a marca da errância permaneceu em Joyce. Seu percurso inicia-se na posição de vagabundo - em latim vagabundus, de vagari (errar, no sentido de vagar) termo que, segundo Le Petit Robert (2001), diz respeito àquele que leva uma vida errante — até com sua arte inventar um lugar para si a ponto de sua obra ser tema de vários e exaustivos estudos pelo mundo.

Joyce nasceu e viveu em Dublin até 1902, quando decidiu cursar Medicina em Paris. Para ele (Ellmann, 1989, p. 147), tanto partir de seu país quanto escrever eram estratégias de combate e estavam intimamente ligados um com o outro. Escrever era uma forma de se exilar, uma vez que de certa forma também é partir, deixar algo de si e ir embora. Em Paris, Joyce viveu tempos difíceis, chegou a viver como vagabundo, passou fome, como relatou em cartas à família. Suas roupas eram puídas, botas gastas e camisas sujas para economizar o gasto da lavanderia. Seus dentes estavam num estado tão ruim que ele não podia tomar uma sopa quente de cebola, sem retorcer-se de dor, o que indica o estado de precariedade material que atravessou. Pouco tempo depois, Joyce retorna a Dublin devido ao grave estado de saúde de sua mãe. Nesse retorno à sua terra natal, ele quase não escrevia, bebia, fazia pequenos empréstimos e andava sem destino pelas ruas a ponto de ser chamado de mendigo. Até mesmo a ideia de 'lar' era rejeitada por Joyce. Como explica em carta endereçada a Nora, Joyce (2012b) rejeitava "toda a ordem social atual e o cristianismo - lar, as virtudes reconhecidas, classes sociais e doutrinas religiosas. Como posso gostar da ideia de lar? Meu lar foi simplesmente um de classe média arruinado por hábitos pródigos os quais herdei" (p. 37). Seu pai era herdeiro de várias propriedades irlandesas, porém todas perdidas em hipotecas e dívidas que o levaram à falência. 
Certa vez, Joyce confessou ao escritor suíço Jacques Mercanton: "Por que lamentar meu talento? Não tenho nenhum. Escrevo tão dolorosamente, tão lentamente. O acaso me dá o de que preciso. Sou como um homem que tropeça: meu pé bate nalguma coisa, olho para baixo, e lá está exatamente aquilo de que necessito" (apud Ellmann, 1989, p. 814). Um homem que tropeça, que erra, é nomeado por Lacan (1975-1976/2007, p. 11-17) em função das duas vertentes que se apresentam na arte de Joyce, como: "Joyce, le sinthome", que ressoa com le saint-homme (santo homem, numa alusão à formação jesuíta do artista e à influência de São Tomás de Aquino) e também como "Joyce, esse pobre-diabo", aludindo a associações possíveis entre a figura do diabo e a do herético. Aqui, Lacan se vale das ressonâncias entre hère, pobre-diabo, e hérétique, herético, lembrando que Joyce (2012b) passa a rejeitar o cristianismo: "Quando era estudante travei uma guerra secreta contra ela [igreja católica] e recusei aceitar as posições que me oferecia. Ao fazer isso eu me tornei um mendigo, mas mantive o meu orgulho" (p. 37).

Pela sua prática de escritor, Joyce ensina sobre o valor da errância, a partir de sua condição de autoexilado. De acordo com a experiência psicanalítica, há algo em nós que erra, que fracassa. Em seu livro Los Descarriados, Vaschetto (2010) "recorre a uma circularidade entre o errar e o erro, o extravio contemporâneo como errância e o extravio como erro" (p. 19). O autor traça uma equivalência entre 'descarriado' (desgarrado, extraviado, perdido, que se afastou do trilho) e errante. Afirma que o humano está contaminado pela experiência do errar e cada um se "orienta como pode no rio agitado dos significantes" (p. 95). Como diz o ditado: "Errar é humano", o que situa o erro em oposição ao acerto ou ao bom caminho. Entretanto, errar tanto pode ser entendido no sentido de cometer erro, enganar-se, como no de vagar, movimentar-se sem destino fixo, vagabundear. Sem poder contar com um referente universal, cada sujeito terá que encontrar ou inventar o que funciona como uma espécie de bússola para se orientar.

\section{Breve reflexão sobre o exílio}

Como Joyce (1916/1987) escreveu em seu Retrato do artista quando jovem: "Havia um ímpeto de marcha errante em seus pés que queimavam querendo partir para os confins da terra. - 'Vamos! Vamos!' - parecia gritar o seu coração" (p. 172). O escritor viajou e manteve-se exilado de seu país natal até a morte. De Dublin, partiu para Trieste, passou pelas cidades 
italianas de Pola e Roma, voltou a Paris e depois Zurique, cidade na qual está enterrado. A obra de Joyce é marcada pela experiência do exílio já que o autor viveu a maior parte da vida fora de seu país de origem, a Irlanda. Uma de suas primeiras obras é a peça teatral Exilados, considerada uma obra autobiográfica, escrita entre 1914 e 1915, quando Joyce sai da Irlanda acompanhado de sua mulher, Nora Barnacle, para se exilar em Trieste.

Joyce se torna exilado não por ter sido expulso de sua terra natal, mas por escolher se retirar dela. A saída do lugar familiar leva-o à errância, a uma busca pelo seu lugar no mundo, e remete à experiência da viagem. Como expõe no Retrato do artista quando jovem (1916/1987), abandona a ideia de abraçar o sacerdócio para, através da arte, "recriar a vida", não sem antes errar, usando o exílio como uma de suas principais armas:

Não servirei àquilo em que não acredito mais, chame-se isso o meu lar, a minha pátria ou a minha igreja: e vou tentar exprimir-me por algum modo de vida ou de arte tão livremente quanto possa, e de modo tão completo quanto possa, empregando para minha defesa apenas as armas que eu me permito usar: silêncio, exílio e sutileza. (p. 244)

$\mathrm{O}$ exilado pode ser tomado como aquele que saiu de sua terra natal em direção ao um novo mundo, no qual o estrangeiro não fosse mais confundido com o inimigo. Ele é chamado por Freud (1915/1992) de Kulturweltbürger, cidadão do mundo culto, aquele que, com a guerra, ficou "desorientado e perplexo em um mundo que se lhe tornou estranho, sua grande pátria desintegrada, seu patrimônio comum devastado, seus cidadãos divididos e aviltados" (p. 282).

O sujeito é um exilado! Exilado da linguagem, uma vez que não há significante que dê conta de seu ser. Exilado do corpo, posto que ter um corpo não lhe é assegurado de antemão; e exilado até mesmo da posição de sujeito. Exilada é toda pessoa impedida de voltar para casa, seja por banimento ou escolha própria. Refletindo sobre o exílio, o crítico literário palestino Edward Said (1984/2003, p. 50-54) o opõe ao nacionalismo. Enquanto este representa um atestado de pertencimento a um lugar, o exílio é marcado pela separação. O exilado está apartado da terra natal, das raízes e do passado. Diante dessa perda, ele é compelido a criar "um novo mundo para governar", daí tantos exilados serem romancistas, jogadores de xadrez, ativistas políticos e intelectuais. O autor sustenta que James Joyce escolheu o exílio para dar força à sua vocação artística. Com base no que apresentou Ellmann na biografia do romancista irlandês, "Joyce arrumou uma querela com a Irlanda e a manteve viva, de maneira a sustentar a mais rigorosa oposição ao que era familiar" 
(Said, 1984/2003, p. 55). O motivo disso seria o fato de o exilado atravessar fronteiras, rompendo assim barreiras do pensamento e da experiência.

Joyce chegou mesmo a afirmar o exílio como condição para compreender sua obra. Ao saber que o escritor dinamarquês Tom Kristensen lera Ulysses longe de sua terra natal, Joyce (apud Ellmann, 1989) comentou: "É preciso estar no exílio para compreender-me". E acrescenta: "Stuart Gilbert me leu quando vivia na Birmânia" (p. 853). A leitura da obra de Joyce demanda que se suporte certo estranhamento, um desprendimento do que é puramente familiar, e aceitar se perder pelos labirintos da linguagem.

\section{Língua e invenção}

Joyce sempre escreveu sobre a Irlanda, mas não era um nacionalista, tampouco acreditava em resgatar as origens, como proposto pelos escritores ligados ao Renascimento, a partir de uma romantização da vida rural e campesina. Em função de ver a Irlanda como um lugar atrasado, o escritor, assim como Stephen Dedalus - protagonista do Retrato do artista quando jovem, que, como destaca Lacan (1975-76/2007), “é Joyce na medida em que decifra seu próprio enigma" (p. 67) — parte para inventar na forja de sua alma a "consciência incriada" de sua raça. Era preciso partir para inventar. Não era possível continuar em Dublin, pois para ele essa cidade sofria de uma espécie de paralisia. Em discussão com o irmão Stanislaus, afirma: "Esta cidade [Dublin] está sofrendo de uma hemiplegia da vontade. Eu não tenho medo de viver" (apud Ellmann, 1989, p. 174). Essa paralisia aparece logo na abertura de Dublinenses (2012a/1914), seu livro de contos sobre Dublin e seus habitantes. Ele sai desse lugar paralisante, assume para si, em seu primeiro romance, o nome Dedalus - um inventor, na mitologia grega, fora o construtor do labirinto do temível Minotauro - e movimenta o cenário literário com sua escrita.

James Joyce fez um uso inventivo da língua, cujo uso idiossincrático, Lacan (1975-76/2007) nos convida a ler em Finnegans Wake: "Leiam as páginas de Finnegans Wake, sem procurar compreender. Isso se lê. Se isso se lê, como me fazia notar alguém que me é próximo, é porque sentimos presente o gozo daquele que escreveu isso" (p. 161). Foi justamente sobre o gozo na escrita que Lacan aprendeu com o artista, assinalando que a linguagem pode ser usada para outra finalidade que não a de comunicar. A língua pode ser utilizada com o intuito de gozar. Joy, marca do nome 
'Joyce', é uma palavra inglesa cuja tradução portuguesa é alegria, deleite, grande prazer. Porém, há ainda outro significado para joy, que é gozo, como destacou Lacan (1975-76/2007) na Conferência "Joyce, o sintoma", proferida na abertura do "V Simpósio Internacional James Joyce", ao afirmar que esse artista "tem no final das contas, uma relação com joy, o gozo [jouissance], tal como ele é escrito na lalíngua que é a inglesa —- por ser essa gozação, por ser esse gozo a única coisa que, do seu texto, podemos pegar. Aí está o sintoma" (p. 162-163). Eis um motivo para capturar o leitor, uma vez que a palavra 'Joyce' faz valer a satisfação e o gozo já presente no próprio nome do autor que ecoa, como ele próprio gostava de lembrar, 'alegria' também contida no nome 'Freud'.

\section{Da invenção ao sinthoma}

Joyce, o sintoma (Lacan, 1975-76/2007, p. 160) diz respeito ao fato de o escritor - trata-se apenas de uma conjectura - ser desabonado do inconsciente. Em língua francesa, o termo dasabonée $e^{1}$ significa ter deixado de ser assinante de algo. Embora trabalhe a mesma matéria, a linguagem, que produz a assinatura do inconsciente, Joyce "é capaz de cancelar essa assinatura ao promover a conjugação entre significantes, não mais com a intenção de produzir sentido, mas fundamentalmente com a finalidade de produção de gozo" (Mandil, 2003, p. 268). Levando-se em conta a trajetória de Joyce, pode-se verter desábonné à l'inconscient para "exilado do inconsciente" (p. 207), tendo em vista a importância dada por Joyce ao exílio, considerado uma de suas armas.

Isso foi o que Lacan detectou em Joyce, notou um outro enlace possível da linguagem, não mais visando o sentido, mas a produção de gozo. Podemos perceber na leitura da obra de Joyce, especialmente em Finnegans Wake, que ele inventava palavras. Mais ainda, Joyce inventou uma nova literatura, feita não para se ler, mas para se escutar, privilegiando não mais o sentido e sim o gozo. Para ele, seus livros não deveriam ser lidos, mas escutados como música. Numa única palavra, por exemplo, riverrun que abre o Finnegans (Joyce, 1939/2004), ressoa:

${ }^{1} \mathrm{Na}$ tradução para o português do seminário $O$ sinthoma, Sérgio Laia optou pelo termo 'desabonado'. 
o francês riverain (ribeirinho), o italiano riverranno (voltarão a vir), o francês rêverons (sonhemos), além, claro, do inglês riverrun (um rio que corre, ou um trecho de um rio) e da possibilidade de um riverann (rio Ana, nome da protagonista), todas possibilidades, diga-se de passagem, em estreita consonância com temas e ideias da abertura do romance. E todas possibilidades simultaneamente válidas. E nenhuma plenamente realizada. (Galindo, 2010, p. 295)

Nesse livro, Joyce utilizou cerca de 65 línguas e dialetos misturados para contar a sua história do mundo, através da morte e ressurreição de Tim Finnegan. O 'novo' é buscado a fim de dotar sua obra de originalidade. Ele inventa artifícios estilísticos, neologismos. Parece brincar com as infinitas possibilidades do uso da língua, aliás, diversas línguas. Antes de criar suas histórias, faz um estudo criterioso, seja sobre a descrição fiel da cidade de Dublin, seja em relação ao estilo do "fluxo da consciência" a partir da análise do monólogo interior. ${ }^{2}$ A escrita de Joyce não é sem uma estruturação, nem invadida por um puro nonsense, senão não poderia ser lida. $\mathrm{O}$ escritor trabalha arduamente, esquematizando, anotando, revisando e reescrevendo a fim de amarrar "os desvarios linguísticos e narrativos encontrados, sobretudo, em Ulisses e em Finnegans Wake. É nesse processo de formalização de sua obra, 460 nesse exercício incessante com o corpus escritural das letras, que Joyce se torna poeta de seu próprio poema" (Laia, 2001, p. 176).

\section{A título de conclusão}

Os não tolos erram. Esta assertiva traduz para o português o título "Les non-dupes errent" (Lacan, 1973-74), que é homofônico a "Les noms du père", os nomes do pai. O tolo é aquele que adere à estrutura e se faz guiar por referências que, na neurose, correspondem à crença no pai, ao nome do pai enquanto este permite nomear as coisas; por isso, o nome do pai é um sinthoma. Nas psicoses, a errância torna-se uma vicissitude decorrente da ausência dessa função, quando o falante não consente em se deixar orientar. Na errância de Joyce descobre-se a invenção de um nome por intermédio da obra e de sua inclusão na posteridade.

${ }^{2}$ Técnica literária - na qual o narrador expõe questões de cunho introspectivo, revelando motivações interiores, pensamentos — que Joyce dizia ter pegado do escritor francês Édouard Dujardin (1861-1949). 
Pelas virtudes da escrita, o mundo se ordena para Joyce. Ele forjou um saber-fazer com seu sinthoma, servindo-se de sua singularidade, de certa precariedade que poderia ser tida como desvantagem, mas não por ele. $\mathrm{O}$ sinthoma é transclínico, presente em qualquer estrutura subjetiva ou quadro clínico. Em contrapartida, sua configuração não ignora a posição subjetiva do falante, uma vez que a singularidade do "sinthoma" está em cada um como uma solução única. Todo falante precisa inventar um modo de habitar o mundo, mas nem todos fazem uma obra, como fez Joyce.

\section{Referências}

American Psychiatric Association. (2014). Manual diagnóstico e estatístico de transtornos mentais - DSM-5. (5 ed.). Porto Alegre: Artmed.

Bloch, W. (1975). Dictionnaire étymologique de la langue française. Paris: PUF.

Ellmann, R. (1989). James Joyce. São Paulo: Globo.

Freud, S. (1992). De guerra y muerte. Temas de actualidad. In Obras Completas (v. 14, pp. 273-303). Buenos Aires: Amorrortu. (Trabalho original publicado em 1915).

Galindo, C. (2010). The Finnecies of music wed poetry: A música e o Finnegans Wake. ScientiaTraductionis, n. 8. Disponível em: <http://www.periodicos.ufsc.br/index. php/scientia/article/view/1980-4237.2010n8p299>. Acesso em: 01 jun. 2013.

Joyce, J. (1987). Retrato do artista quando jovem. Rio de Janeiro: Ediouro. (Trabalho original publicado em 1916).

Joyce, J. (2003). Exilados. Tradução e introdução de Alípio Correia de França Neto. São Paulo: Iluminuras. (Trabalho original publicado em 1918).

Joyce, J. (2004). Finnegans Wake / Finnicius Revém. (2 ed.). Cotia, SP: Ateliê Editorial. (Trabalho original publicado em 1939).

Joyce, J. (2012a). Dublinenses. São Paulo: Hedra. (Trabalho original publicado em 1914).

Joyce, J. (2012b). Cartas a Nora. Organização, apresentação e tradução Sérgio Medeiros e Dirce Waltrick do Amarante. São Paulo: Iluminuras.

Lacan, J. (1973-74). O seminário. Livro 21. Os não tolos erram. Inédito.

Lacan, J. (2007). O seminário. Livro 23. O sinthoma. Rio de Janeiro: Jorge Zahar. (Trabalho original publicado em 1975-76).

Laia, S. (2001). Os escritos fora de si-Joyce, Lacan e a loucura. Belo Horizonte: Autêntica/FUMEC. 
Le Robert Staff (2001). Le Petit Robert. Paris: Le Robert. CD-ROM.

Mandil, R. (2003). Os efeitos da letra: Lacan leitor de Joyce. Rio de Janeiro/Belo Horizonte: Contra Capa/Faculdade de Letras UFMG.

Said, E. (2003). Reflexões sobre o exílio. In Reflexões sobre o exílio e outros ensaios. São Paulo: Companhia das Letras. (Trabalho original publicado em 1984).

Tissié, P. (1887). Les aliénés voyageurs: Essai médico-psychologique. 117f. Thèse (Doctorat en Médecine), Faculté de Médicine et de Pharmacie de Bordeaux, Bordeaux, 1887.

Vaschetto, E. (2010). Los descarriados - clínica del extravio mental: Entre la errancia y el yerro. Buenos Aires: Grama Ediciones.

\section{Resumos}

(Wandering: beyond a pathological symptom)

This paper discusses the issue of wandering in a transtructural form, as a vicissitude that occurs in different clinical structures, and verifies its positivity: the possibility, from erring, to building up something new. Based on the connection between psychoanalysis and art, the paper refers to the writing of James Joyce to investigate the wandering and analyze the path taken by the writer, initially in a vagabond position, wandering, until he invented with his art a place for himself in the world.

Key words: Psychoanalysis, wandering, exile, invention

(L'errance: par ailleurs d'um syntôpme patologique)

Cet article discute la question de l'errance de façon transestructurel, tel qu'une vicissitude présente dans les différentes estructures cliniques, et verifie sa positivité: la possibilité d'à travers de l'erreur, construire à soi même quelque chose nouvelle. À travers la connexion entre la psychanalyse et l'art, le travaille rapport à l'écrite de James Joyce pour enquêter l'errance et analyser le trajet realisé par l'écrivain, d'abord dans le rôle de vagabond, mais même avec son art créer un lieu pour soi-même.

Mots clés: Psychanalyse, errance, exil, invention

(La errancia: más allá de un síntoma patológico)

Este artículo discute la cuestión de la errancia de forma transestructural, como una vicisitud presente en las diferentes estructuras clinicas, y verifica su positividad: la posibilidad de, a partir del errar, construirse algo nuevo. Basado en la conexión 
entre el psicoanálisis y el arte, el trabajo se refiere a la escritura de James Joyce para investigar la errancia y analizar el recurrido del escritor, inicialmente en la posición de vagabundo, errante, para después con su arte inventar un lugar para sí en el mundo.

Palabras clave: Psicoanálisis, errancia, exilio, invención

(Die Irrfahrt: jenseits eines pathologisches Symptom)

Dieser Artikel untersucht das Problem des Irrens vom transstrukturalen Typ, als einen in verschiedenen klinischen Strukturen präsenten Wandel, und überprüft seinen positiven Charakter: die Möglichkeit, ausgehend von der Tatsache des Irrens, etwas Neues zu konstruieren. Auf der Grundlage einer Verbindung von Psychoanalyse und Kunst, stützt sich die Arbeit auf das Schreiben von James Joyce, um das Irren zu erforschen und den von diesem Schriftsteller durchlaufenen Weg zu analysieren, zunächst in der Position eines Vagabunden, eines Irrenden, um schließlich mit seiner Kunst einen Platz für sich in der Welt zu erfinden.

Schlüsselwörter: Psychoanalyse, Irrfahrt, Exil, Erfindung

\section{（流浪：为了超越自我病兆）}

本文讨论了自我流浪的问题, 作者跨越了临床分析的框架, 根据不同的临 床问诊记录里出现的人生起伏, 讨论了自我流浪的正面性: 联系心理分析学和 文学艺术, 作者分析了作家詹姆斯・乔伊斯的作品中有关流浪的叙述, 解读了作 家乔伊斯本人的流浪历程, 首先作为一个流浪汉, 一个精神流亡者, 直到他的 艺术才能给他在世界上创造了一席之地。

关键词: 心理分析, 流浪, 流放, 创造

Citação/Citation: Soares, A.C., Bastos, A. (2016, setembro). Errância para além de um sintoma patológico. Revista Latinoamericana de Psicopatologia Fundamental, 19(3), 452-464.

Editores do artigo/Editors: Prof. Dr. Manoel Tosta Berlinck e Profa. Dra. Sonia Leite

Recebido/Received: 13.4.2015/ 4.13.2015 Aceito/Accepted: 21.6.2015 / 6.21.2015 


\section{ARTIGOS}

Copyright: (C) 2009 Associação Universitária de Pesquisa em Psicopatologia Fundamental/ University Association for Research in Fundamental Psychopathology. Este é um artigo de livre acesso, que permite uso irrestrito, distribuição e reprodução em qualquer meio, desde que o autor e a fonte sejam citados / This is an open-access article, which permits unrestricted use, distribution, and reproduction in any medium, provided the original authors and sources are credited.

Financiamento/Funding: Esta pesquisa é financiada pela Coordenação de Aperfeiçoamento de Pessoal de Nível Superior - Capes / The research is funded by the Coordenação de Aperfeiçoamento de Pessoal de Nível Superior - Capes.

Conflito de interesses/Conflict of interest: As autoras declaram que não há conflito de interesses / The authors have no conflict of interest to declare.

\section{ana Claudia Soares}

Psicóloga; Doutoranda no Programa de Pós-Graduação em Teoria Psicanalítica da Universidade Federal do Rio de Janeiro. Bolsista da CAPES - Ministério da Educação do Brasil, Brasília, DF, a quem agradecemos pelo apoio financeiro (Programa de Doutorado Sanduíche no Exterior - PDSE) na realização desta pesquisa.

Estrada do Cafundá, 1757/611, bloco 5, Taquara

22725-030 Rio de Janeiro, RJ, Brasil

ana_soares@oi.com.br

\section{Angélica Bastos}

Psicanalista; Prof. Associado II no Programa de Pós-Graduação em Teoria Psicanalítica da Universidade Federal do Rio de Janeiro - UFRJ (Rio de Janeiro, RJ, Br); Bolsista de produtividade em pesquisa do Conselho Nacional de Desenvolvimento Científico e Tecnológico - CNPq (Brasília, DF, Br); Doutora em Psicologia Clínica pela Pontifícia Universidade Católica de São Paulo - PUC-SP (São Paulo, SP, Br).

Av. Atlântica, 554/902 - Leme

22010-000 Rio de Janeiro, RJ, Br.

abastosg@terra.com.br

\section{(cc) BY-NC}

This is an open-access article, which permits unrestricted use, distribution, and reproduction in any medium for non-commercial purposes provided the original authors and sources are credited. 